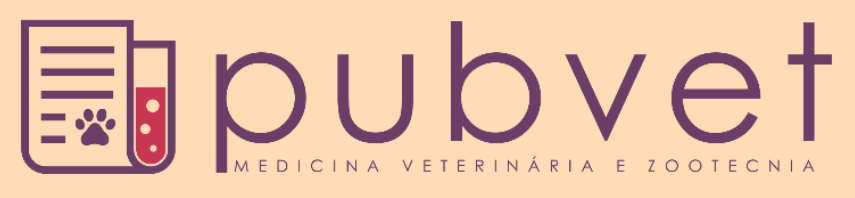

https://doi.org/10.31533/pubvet.v14n6a587.1-8

\title{
Diagnóstico do perfil do consumidor de carne suína no município de Olho d'Água - PB
}

\author{
Rosa Maria dos Santos Pessoa ${ }^{1} \bullet$, Dinah Correia da Cunha Castro Costa ${ }^{2}$, Gelhianne Gislayne \\ ${\text { Bezerra } \operatorname{Ramos}^{2} \theta \text {, Raiany Meirelli dos Anjos Rodrigues }}^{2}{ }^{\circ}$, Joyanne Mirelle de Sousa Ferreira ${ }^{10}$, \\ Anderson Antonio Ferreira da Silva ${ }^{1}$, Fleming Sena $\operatorname{Campos}^{30}$, Aicanã Santos de Miranda ${ }^{4}{ }^{\circ}$, \\ Cleyton de Almeida Araújo ${ }^{3}$, Amélia de Macedo $^{4} \bullet$, Glayciane Costa Gois ${ }^{4 *}$
}

${ }^{1}$ Universidade Federal de Campina Grande. Patos - PB, Brasil.
${ }^{2}$ Universidade Federal da Paraíba. Areia - PB, Brasil.
${ }^{3}$ Universidade Federal Rural de Pernambuco. Garanhuns - PE, Brasil.
${ }^{4}$ Universidade Federal do Vale do São Francisco. Petrolina - PE, Brasil.
${ }^{*}$ Autor para correspondência, E-mail:glayciane gois@yahoo.com.br

Resumo. Com a necessidade de entender o comportamento dos consumidores, o presente estudo foi realizado com o objetivo de caracterizar o perfil do consumidor de carne suína do município de Olho d'água no estado da Paraíba. Foram aplicados 91 questionários semiestruturados, durante os meses de setembro à novembro de 2019. As perguntas permitiram verificar aspectos inerentes ao perfil do consumidor, tais como sexo, idade, escolaridade, carne preferida para consumo, consumo de carne suína, motivo de não consumir, consumo de produtos cárneos feitos com carne suína, frequência de consumo, preferência dos cortes suínos, se o entrevistado acha que a carne suína traz benefícios à saúde e se a propaganda exerce influência na compra da carne suína. Dos consumidores entrevistados, $56 \%$ eram do sexo masculino e $44 \%$ do sexo feminino com renda mensal variando entre 260,00 e 500,00 reais (53\%). A maioria dos entrevistados apresentou faixa etária entre 18 e 30 anos (38\%) e com o ensino fundamental incompleto (43\%). A carne suína apresentou menor preferência de compra (10\%), apesar de $57 \%$ dos entrevistados afirmarem que a consomem principalmente nos finais de semana (45\%). O não consumo dessa carne por $43 \%$ dos entrevistados ocorre por acharem que é uma carne gordurosa (51\%), por questões sanitárias (29\%), por não gostarem do sabor (12\%) e por acharem que é um produto caro (9\%). O consumo de produtos cárneos elaborados com carne suína é regular, $43 \%$ dos entrevistados consomem presunto ou apresuntado, 32\% consomem salsicha e mortadela, $15 \%$ consomem linguiça e, em menores proporções, $7 \%$ consomem bacon e 1\% consomem o salame. Em relação aos principais cortes suínos, 52\% dos entrevistados preferem a costela, seguida da bisteca (20\%). Dos entrevistados 53\% afirmaram que não traz benefícios e $47 \%$ que existem benefício nessa carne. Apenas $24 \%$ dos entrevistados acreditam que a propaganda exerce influência na compra da carne suína. $O$ consumo de carne suína ainda é pequeno quando comparada as demais carnes. Um dos fatores que impede esse consumo são os costumes regionais. Sugerem-se campanhas de aumento de consumo da carne suína baseadas em preços baixos, esclarecimentos sobre as qualidades nutricionais e sanitárias, oferecimentos de cortes diferenciados e novas formas de preparo.

Palavras chave: produto de origem animal, satisfação dos consumidores, suinocultura, tecnologia de alimentos

\section{Diagnosis of pork meat consumer profile in Olho d'Água - PB}

Abastract. With the need to understand the behavior of consumers, this study was carried out with the objective of characterizing the pork meat consumers profile in the municipality of Olho d'água in Paraíba state. Ninety-one semi-structured questionnaires were applied 
from September to November 2019. The questions allowed to verify aspects inherent to the consumer's profile, such as gender, age, education, favorite meat for consumption, pork consumption, reason for not consume, consumption of meat products made from pork, frequency of consumption, preference for pork cuts, if the respondent thinks that pork has health benefits and if advertising influences the purchase of pork. Of the consumers interviewed $56 \%$ were male and $44 \%$ female with monthly income ranging between 260 and 500 reais $(53 \%)$. Most respondents were aged between 18 and 30 years (38\%) and had incomplete elementary school $(43 \%)$. Pork showed lower purchase preference $(10 \%)$, although $57 \%$ of respondents stated that they consume it mainly on weekends (45\%). The non-consumption of this meat by $43 \%$ of respondents occurs because they think it is fatty meat (51\%), for health reasons (29\%), because they do not like the taste (12\%) and because they think it is an expensive product (9\%). The consumption of meat products made with pork is regular, $42 \%$ of respondents eat ham or ham, $32 \%$ eat sausage and mortadella, $15 \%$ eat sausage and, to a lesser extent, $7 \%$ eat bacon. and $1 \%$ consume salami. Regarding the main pork cuts, $52 \%$ of respondents prefer the rib, followed by the pork chop (20\%). Of those interviewed 53\% said that it has no benefits and $47 \%$ that there is benefit in this meat. Only $24 \%$ of respondents believe that advertising influences the purchase of pork. The consumption of pork is still small when compared to other meats. One of the factors that prevents this consumption is the regional customs. Campaigns for increasing pork consumption based on low prices, clarifications on nutritional and health qualities, offerings of differentiated cuts and new forms of preparation are suggested.

Keywords: animal product, consumer satisfaction, food technology, pig farming

\section{Diagnóstico del perfil del consumidor de carne porcina en Olho d'Água - PB}

Resumen. Con la necesidad de comprender el comportamiento de los consumidores, este estudio se realizó con el objetivo de caracterizar el perfil de los consumidores de carne de cerdo en el municipio de Olho d'água en el estado de Paraíba. Se aplicaron noventa y un cuestionarios semiestructurados de septiembre a noviembre de 2019. Las preguntas permitieron verificar aspectos inherentes al perfil del consumidor, como género, edad, educación, carne favorita para el consumo, consumo de carne de cerdo, razón por la cual no consume, consumo de productos cárnicos hechos de carne de cerdo, frecuencia de consumo, preferencia por cortes de carne de cerdo, si el encuestado cree que la carne de cerdo tiene beneficios para la salud y si la publicidad influye en la compra de carne de cerdo. De los consumidores entrevistados, 56\% eran hombres y $44 \%$ mujeres con ingresos mensuales que oscilaban entre 260.00 y 500.00 reales (53\%). La mayoría de los encuestados tenían entre 18 y 30 años (38\%) y con educación primaria incompleta (43\%). La carne porcina mostró menor preferencia de compra (10\%), aunque el $57 \%$ de los encuestados declaró que la consumen principalmente los fines de semana (45\%). El $43 \%$ de los encuestados no consume esta carne porque piensan que es carne grasa (51\%), por razones de salud (29\%), porque no les gusta el sabor (12\%) y porque piensan que es un producto caro (9\%). El consumo de productos cárnicos hechos con carne de cerdo es regular, el $43 \%$ de los encuestados come jamón o derivados, el $32 \%$ come salchichas y mortadela, el $15 \%$ come longaniza y, en menor medida, el $7 \%$ come bacon y $1 \%$ consume salami. En cuanto a los principales cortes de carne de cerdo, el 52\% de los encuestados prefieren la costilla, seguida de la chuleta (20\%). De los entrevistados, el 53\% dijo que no tiene beneficios y el $47 \%$ que hay beneficios en esta carne. Solo el $24 \%$ de los encuestados cree que la publicidad influye en la compra de carne de cerdo. El consumo de carne de cerdo todavía es pequeño en comparación con otras carnes. Uno de los factores que impide este consumo son las costumbres regionales. Se sugieren campañas para aumentar el consumo de carne de cerdo en base a precios bajos, aclaraciones sobre las cualidades nutricionales y de salud, ofertas de cortes diferenciados y nuevas formas de preparación.

Palabras clave: cría de cerdos, producto animal, satisfacción del consumidor, tecnología alimentaria 


\section{Introdução}

O suíno foi domesticado com a finalidade de alimentação pelos povos que deixaram de ser nômades. O impasse sobre o consumo da carne é um assunto antigo e sempre foi cercado de preconceitos, devido às crenças populares e religiosas e a forma como os animais era criados. Hoje em dia, a carne suína vem sendo explorada e bastante apreciada por ser uma carne que tem uma grande aceitabilidade pelo mercado consumidor, por conta do sabor extremamente agradável. No entanto, uma grande parte da população não a consome por receio de se contaminar com alguma doença ou acreditando que a carne possui altos índices de gordura (Anjos et al., 2018).

A carne suína é a fonte de proteína animal mais consumida no mundo, sendo praticamente o dobro da carne bovina (FAPRI, 2019). Entretanto, no Brasil, a carne bovina é a mais consumida, com o Brasil ocupando o terceiro lugar como o maior produtor e o quarto maior exportador (ANUALPEC, 2019). A carne suína não ocupou um lugar de destaque pelos brasileiros no seu consumo, sendo aceito em apenas $55 \%$ dos lares, enquanto a carne bovina tem a aceitabilidade de $93 \%$ e a carne de frango de $90 \%$ (Guerrero et al., 2018; Kirinus et al., 2013a). Em termos mundiais, a carne suína é a fonte de proteína animal (exceto leite) mais produzida e consumida pela população, com 30\% (FAPRI, 2019). Seguida pela carne de frangos, com 23\%, ovos de galinha (18\%) e carne bovina (18\%) (FAPRI, 2019). Estas quatro fontes correspondem a $88 \%$ da proteína animal consumida mundialmente (Gentilini \& Anciuti, 2013). A produção mundial de carne suína alcançou as 104,363 milhões de toneladas em 2012, a China foi o país que ocupou a primeira posição em produção mundial, seguido pela União Europeia e em terceiro lugar os Estados Unidos da América (FAPRI, 2019). Já no Brasil a produção representou 3,1\% da produção mundial (ANUALPEC, 2019).

A carne suína é um alimento nobre para o homem, devido à produção de energia, a função plástica na formação de novos tecidos orgânicos e a regulação dos processos fisiológicos. Ela representa uma excelente fonte de proteínas de alto valor biológico, contribuindo na dieta por apresentar todos os aminoácidos essenciais e vitaminas do complexo B, fundamentais ao funcionamento do organismo, além de apresentar uma boa digestibilidade (A. S. Santos et al., 2017). Pesquisas mostram a importância do consumo da carne suína para o tratamento de doenças, como hipertensão arterial e anemia. Uma das virtudes da carne suína é o seu alto teor de potássio, pois ele ajuda a regular os níveis de sódio no corpo, exigindo menos sal para consumo. A carne suína é pobre em sódio e rica em potássio. A grande maioria dos estudos mostra que a ingestão de uma grande quantidade de sal aumenta a pressão arterial e, para o controle da pressão arterial, uma das recomendações é que a relação potássio-sódio seja pequena. A carne suína possui a razão potássio-sódio em torno de 7, ou seja, é altamente favorável ao controle da pressão arterial (Resende \& Campos, 2015).

A carne suína é também recomendada para crianças em fase de crescimento, pois ela apresenta proteínas de alto valor biológico, ácidos graxos monoinsaturados, vitaminas do complexo $\mathrm{B}$, ferro e selênio. Dessa forma, a carne suína deve ser mais uma opção nutricionalmente adequada ao cardápio escolar, pois seus nutrientes são indispensáveis para o crescimento progressivo de crianças nessa idade escolar (Resende \& Campos, 2015). Um dos fatores decisivos para o aumento do consumo de carne suína está na necessidade de garantir que o produto atenda as perspectivas dos consumidores. $\mathrm{O}$ consumidor é que determina o que quer comprar e o mercado deve se adequar as demandas dos consumidores (Oliveira et al., 2017). O reconhecimento por parte da indústria de carnes dos possíveis fatores competitivos apontados pelos consumidores pode ser uma ferramenta de grande importância para a criação de estratégias competitivas para o setor como um todo, como para o setor de distribuição, uma vez que é este quem tem o contato direto com o consumidor (Ahrens, 2017).

Com a necessidade de entender o comportamento dos consumidores, pesquisas e estudos vêm sendo realizados ao longo do tempo. Vários autores têm procurado compreender as razões que levam o consumidor a escolher determinado produto, quantidade, momento e local específico em detrimento de outros (Guerrero et al., 2018). Além disso, indústrias estão reconhecendo a importância de entender o comportamento do consumidor, obtendo assim um maior sucesso na tomada de decisões (Pinheiro et al., 2011). Neste contexto, o presente estudo foi realizado com o objetivo de caracterizar o perfil do consumidor de carne suína do município de Olho d'água no estado da Paraíba. 


\section{Material e métodos}

A pesquisa foi realizada na cidade de Olho d'Água - Paraíba. O município de Olho d'Água está localizado no estado da Paraíba, na microrregião de Piancó, distante da capital do estado da Paraíba a $380 \mathrm{~km}$ com uma área territorial de $596 \mathrm{~km}^{2}$. Sua população de acordo com o IBGE (2017) é de 6.931 habitantes. O município está incluído na área geográfica de abrangência do semiárido brasileiro, tendo com critérios o índice pluviométrico, o índice de aridez e o risco e seca. Sua economia baseia-se principalmente no setor de serviços.

Foi realizada uma pesquisa estilo "Survey", do tipo exploratória e descritiva, a qual é utilizada para a obtenção de informações por intermédio de uma entrevista com os participantes, onde são feitas perguntas acerca do tema que se está estudando por meio da aplicação de um questionário estruturado para obter uma padronização do processo de coleta de dados (Pessoa et al., 2018). A pesquisa foi realizada em estabelecimentos da zona urbana e com a população da zona rural. Foram aplicados questionários semiestruturados, durante os meses de setembro a novembro de 2019. A população focalizada foi composta por homens e mulheres acima de 16 anos, onde foram realizadas 91 entrevistas. As perguntas permitiram verificar aspectos inerentes ao perfil do consumidor, tais como sexo, idade, escolaridade, carne preferida para consumo, consumo de carne suína, motivo de não consumir, consumo de produtos cárneos feitos com carne suína, frequência de consumo, preferência dos cortes suínos, se o entrevistado acha que a carne suína traz benefícios à saúde e se a propaganda exerce influência na compra da carne suína.

Após a aplicação do questionário, foi montado um banco de dados em planilha eletrônica (EXCEL) que possibilitou a sua sistematização. Os resultados após tabulados foram apresentados em proporções de respostas $(\%)$.

\section{Resultados e discussão}

A aplicação de questionários em pesquisas é bastante utilizada para caracterizar a opinião da população sobre um assunto específico. Este processo auxilia o pesquisador a elaboração de perfis de consumo e comportamento, além das aplicações de diversos diagnósticos (Kirinus et al., 2013b). A amostragem é uma ferramenta utilizada quando a população (conjunto total dos elementos que se busca analisar) é composta por um número muito grande de elementos, o que impossibilita o acesso a toda a população para a coleta dos dados. Assim, uma amostra é selecionada, com número e característica significativos de elementos dentro da população, para que os resultados da amostra sejam suficientemente informativos para se inferir conclusões sobre os parâmetros de toda a população em análise (Kirinus et al., 2013b).

Dos consumidores entrevistados $56 \%$ foram do sexo masculino e $44 \%$ do sexo feminino com renda mensal variando entre 260,00 e 500,00 reais $(53 \%)$. A maioria dos entrevistados apresentaram uma faixa etária entre 18 e 30 anos (38\%) e com o ensino fundamental incompleto (436\%) (Tabela 1).

Tabela 1. Sexo, renda mensal, idade e nível de escolaridade dos entrevistados.

\begin{tabular}{llr}
\hline Variáveis & & $(\%)$ \\
\hline \multirow{2}{*}{ Sexo } & Masculino & $56,00 \%$ \\
& Feminino & $44,00 \%$ \\
\hline \multirow{3}{*}{ Renda mensal } & $\mathrm{R} \$ 260-500$ & $53,00 \%$ \\
& $\mathrm{R} \$ 500-1000$ & $33,00 \%$ \\
& Acima de R \$ 1000 & $14,00 \%$ \\
\hline \multirow{3}{*}{ Idade } & $18-30$ anos & $38,00 \%$ \\
& $31-45$ anos & $30,00 \%$ \\
& $46-59$ anos & $27,00 \%$ \\
& Acima de 60 anos & $5,00 \%$ \\
\hline \multirow{3}{*}{ Escolaridade } & Ensino fundamental completo & $3,30 \%$ \\
& Ensino médio completo & $13,19 \%$ \\
& Ensino fundamental incompleto & $42,86 \%$ \\
& Ensino médio incompleto & $34,07 \%$ \\
& Superior & $3,30 \%$ \\
& Superior incompleto & $3,30 \%$ \\
\hline
\end{tabular}


Nas refeições diárias é indispensável o consumo de carne, seja qual o seu tipo. Apesar de ser um alimento rico em proteínas e nutrientes, o ideal é que a pessoa consuma diariamente cerca de $100 \mathrm{~g}$ do alimento, segundo as normas do Ministério da Saúde, o que na prática corresponde a um bife pequeno (A. S. Santos et al., 2017). Em relação a preferência de compra das carnes para consumo, a maioria dos entrevistados prefere comprar carne bovina (53\%), peixe (24\%) e frango (13\%), nesta ordem (Tabela 2). A carne suína apresentou menor preferência de compra (10\%), apesar de 57\% dos entrevistados afirmarem que a consomem principalmente nos finais de semana, potencialmente em eventos festivos (45\%). O não consumo dessa carne por $43 \%$ dos entrevistados ocorre por acharem que é uma carne gordurosa $(51 \%)$, por questões sanitárias (29\%), por não gostarem do sabor $(12 \%)$ e por acharem que é um produto caro $(9 \%)$.

Tabela 2. Preferência dos consumidores de carne suína no município de Olho d'Água - Paraíba.

\begin{tabular}{|c|c|c|}
\hline Variáveis & & $\%$ \\
\hline \multirow{4}{*}{ Preferência de compra } & Bovino & $52,75 \%$ \\
\hline & Peixe & $24,18 \%$ \\
\hline & Suína & $9,89 \%$ \\
\hline & Frango & $13,19 \%$ \\
\hline \multirow{2}{*}{ Consumo de carne suína } & Sim & $57,00 \%$ \\
\hline & Não & $43,00 \%$ \\
\hline \multirow{4}{*}{ Frequência de consumo } & Diariamente & $16,00 \%$ \\
\hline & Semanalmente & $45,00 \%$ \\
\hline & Quinzenalmente & $34,00 \%$ \\
\hline & Mensalmente & $5,00 \%$ \\
\hline \multirow{4}{*}{ Motivo de não consumir } & Gordurosa & $50,55 \%$ \\
\hline & Questões sanitárias & $28,57 \%$ \\
\hline & Preço & $8,79 \%$ \\
\hline & Sabor & $12,09 \%$ \\
\hline \multirow{5}{*}{ Consumo de produtos cárneos } & Salsicha/mortadela & $34,07 \%$ \\
\hline & Presunto/apresuntado & $42,86 \%$ \\
\hline & Linguiça & $15,38 \%$ \\
\hline & Salame & $1,10 \%$ \\
\hline & Bacon & $6,59 \%$ \\
\hline \multirow{6}{*}{ Cortes cárneos } & Bisteca & $20,00 \%$ \\
\hline & Costela & $52,00 \%$ \\
\hline & Pernil & $13,00 \%$ \\
\hline & Picanha & $10,00 \%$ \\
\hline & Filé mignon & $04,00 \%$ \\
\hline & Lombo & $01,00 \%$ \\
\hline \multirow{2}{*}{ Benefícios à saúde } & Sim & $47,00 \%$ \\
\hline & Não & $53,00 \%$ \\
\hline \multirow{2}{*}{ Propaganda influencia a compra } & Sim & $24,00 \%$ \\
\hline & Não & $76,00 \%$ \\
\hline
\end{tabular}

No Brasil a carne suína ainda é pouco consumida comparativamente às demais fontes de proteína animal. Esse fato está ligado principalmente a um fator cultural negativo associado à produção de suínos. Onde desde a antiguidade, os povos diziam que a carne suína transmitia enfermidades aos seres humanos, com destaque para Taenia solium. Embora esse fator tenha sido desmistificado pela ciência, ao considerar as modernas técnicas de produção suinícola, a relação entre consumo de carne suína e sanidade permanece até os dias atuais (Santos et al., 2019; Souza et al., 2016). Segundo o ANUALPEC (2019), o brasileiro consome em torno de $80 \mathrm{~kg}$ de carne por ano e destes, próximo a $11 \mathrm{~kg}$ é de carne suína. Na América do Sul o consumo de carne total chega a $70 \mathrm{~kg}$ per capita e destes aproximadamente 10 kg é de carne suína. Nestes países o consumo de carne total é elevado, sendo a Argentina um grande consumidor chegando a $92 \mathrm{~kg}$ por pessoa ano. A carne suína disponível atualmente não merece os conceitos errôneos de que é gordurosa e faz mal à saúde. Ao contrário, trata-se de um alimento nutritivo e saboroso, muito equilibrado em sua composição e deveria ocupar mais espaço na mesa do consumidor brasileiro. 
O consumo de carne suína ocorre principalmente sob a forma industrializada. Na presente pesquisa observa-se que o consumo de produtos cárneos elaborados com carne suína é regular, onde $100 \%$ dos entrevistados os consomem, sendo que $43 \%$ dos entrevistados consomem presunto ou apresuntado, $32 \%$ consomem salsicha e mortadela, $15 \%$ consomem linguiça e, em menores proporções, $7 \%$ consomem bacon e $1 \%$ consomem o salame. Assim, é possível concluir indiretamente que a carne suína, em suas várias formas, não é consumida por apenas 57\% dos entrevistados como observado anteriormente. Com isto é possível inferir que os participantes da pesquisa desconhecem a composição dos embutidos e os consomem, mesmo tendo carne suína em sua composição ou ainda consomem sabendo da existência de carne suína na composição, porém aceitam a carne suína nesta forma, mesmo avaliando-a como uma carne que apresenta variáveis não agradáveis como alto teor de gordura e por questões sanitárias.

No Brasil, existe uma grande variedade de produtos derivados da carne suína: embutidos, salgados, defumados, pré-cozidos e semiprontos, tendo qualidade, marcas e preços diferenciados (Dueli et al., 2018). Assim, atingindo consumidores de todas as classes econômicas. Existe uma variedade de embutidos que diferem de acordo com o processamento e teor de umidade. Embutidos cárneos frescos são obtidos da mistura de carne crua e não passam por tratamento térmico, como exemplo a linguiça frescal (Alcantara et al., 2012). Embutidos secos crus passam por um processo de desidratação parcial, como o salame, que também é classificado como um produto fermentado (Vedovatto et al., 2019). A salsicha e a mortadela passam por um processo de emulsificação seguido de tratamento térmico (Orsolin et al., 2015). Existem também os produtos curados e maturados como o presunto suíno, nos quais são adicionados sais de cura e condimentos, com o objetivo de conservação e melhoria nas propriedades sensoriais. O bacon é um produto cárneo defumado que pode ser produzido através da defumação natural ou aplicação de fumaça líquida, que melhora as características organolépticas do produto, valorizandoo e agregando valor, além de possuir efeito conservante (Soletti, 2018).

Em relação aos principais cortes suínos, $52 \%$ dos entrevistados preferem a costela, seguida da bisteca (20\%) devido à facilidade na hora do preparo, já que estes cortes geralmente são consumidos assados ou fritos. O lombo, que apresentou uma menor preferência pelos entrevistados, é uma das carnes mais magras do animal, pois apresenta uma menor concentração de gordura, sendo considerado mais saudável do que alguns cortes de frango. $\mathrm{O}$ baixo consumo pode estar relacionado ao preço, devido ser um corte nobre, que muitos consumidores não têm condições de adquirir esse produto.

Santos et al. (2019), analisando o perfil dos consumidores de carne suína e derivados em SatubaAlagoas, observaram que neste município os consumidores têm preferência pelos cortes bisteca (55\%) e costela (17\%). Merlini et al. (2014) realizando a caracterização do consumidor e do mercado da carne suína no município de Umuarama - Paraná, verificaram que $23 \%$ dos entrevistados dizem que os cortes que mais aparecem em seus cardápios são a bisteca e o lombo, $15 \%$ costela e pernil, $35 \%$ consomem mais de um corte e $37 \%$ todos os cortes. Silva \& Silva (2010) em estudo e avaliação do consumidor de carne suína "in natura" e industrializada na microrregião de Guarabira - Paraíba, observaram que a maior preferência dos entrevistados foi pela bisteca (33\%), costela (15\%) e pernil (15\%). Bezerra et al. (2007) ao caracterizarem o perfil do consumidor e do mercado da carne suína na microrregião de Campina Grande - Paraíba demonstraram maior preferência de consumo por bisteca $(52,3 \%)$ seguida da costela $(27,5 \%)$. Isto demonstra que a preferência por um corte cárneo também está relacionada aos hábitos de consumo de cada região.

Dos entrevistados 53\% afirmaram que não traz benefícios e 47\% que existem benefício nessa carne. Estudos realizados pelo United States Department of Agriculture (USDA), aponta que a carne de porco possui menor teor de colesterol e sódio que a carne bovina e a de frango. O perigo está na qualidade da produção da carne, pois existe a possibilidade de contaminação do rebanho por microrganismos. Portanto, antes de comprar uma carne, é interessante se saber a origem desse produto para ter a certeza que foi cumprida as exigências estabelecidas pelo serviço de inspeção da secretaria da agricultura e da vigilância sanitária (Magalhães \& Magalhães, 2017).

Segundo Dueli et al. (2018), a carne suína é uma excelente alternativa de proteína animal nas dietas por ser uma fonte proteica de alto valor biológico, uma vez que fornece todos os aminoácidos essenciais necessários para a síntese proteica do organismo. Dentre outras características, destaca-se a grande disponibilidade de tiamina, vitamina que compõe o metabolismo energético e que contribui com a saúde do 
sistema nervoso e muscular. Assim, por ser rica em nutrientes é capaz de oferecer diversos benefícios para a saúde humana. Contudo, a maioria da população desconhece estas informações e ainda carregam mitos e conceitos equivocados sobre a sua qualidade. Muitos consumidores relatam que a carne suína é "carregada", um termo utilizado regionalmente, para aqueles alimentos que fazem mal à saúde, aumentam níveis de colesterol ou produzem reações alérgicas, provavelmente por acharem ser mais gordurosas ou prejudicar processos inflamatórios no corpo humano. Destacando assim, que ainda existem diversos mitos por trás da carne suína.

Apenas $24 \%$ dos entrevistados acreditam que a propaganda exerce influência na compra da carne suína. Os consumidores já têm uma ideia fixa de que não é saudável esse produto e mesmo com propagandas ainda se mantem irredutíveis sobre esse alimento. Merlini et al. (2014) citam que a frequência de consumo de carne suína poderia ser aumentada, a partir da realização de campanhas locais, a fim de melhor esclarecer e informar os consumidores. Grande parte dos entrevistados que consomem esta proteína animal é apreciador do seu sabor e não consideram apenas o preço como empecilho para o consumo. Além disso, seria necessário realizar campanhas competentes de marketing a fim de obter o sucesso na transmissão destas vantagens ao público consumidor de produto. Assim, para que isso ocorra, deve-se comprovar a não-restrição do seu consumo e priorizar a passagem de conhecimentos nutricionais e valores reais quanto à sua eficácia em uma alimentação saudável. $\mathrm{O}$ caminho a ser percorrido na busca do esclarecimento da verdade deverá ser longo e difícil, pois a quebra de tabus e mitos pode durar mais que uma geração, os criadores de suínos deveriam criar um diferencial para reforçar a imagem do produto de boa qualidade. Desta forma, à medida que o consumidor reconhece o parâmetro de qualidade, devidamente divulgado, através dos meios de comunicação, ganha confiança no produto (Santos, 2012).

\section{Conclusão}

Os resultados obtidos mostraram que o consumo de carne suína ainda é pouco quando comparada com as demais carnes. Que um dos fatores que impede esse consumo são os costumes regionais. Os principais motivos segundo os entrevistados para não consumir a carne suína foram alto teor de gordura e doenças causadas por essas carnes. Sugerem-se campanhas de aumento de consumo da carne suína baseadas em preços baixos, esclarecimentos sobre as qualidades nutricionais e sanitárias, oferecimentos de cortes diferenciados e novas formas de preparo.

\section{Referências bibliográficas}

Ahrens, R. B. (2017). A gestão estratégica na administração. Atena Editora.

Alcantara, M., Morais, I. C. L., Matos, C., \& Souza, O. da C. C. (2012). Principais microrganismos envolvidos na deterioração das características sensoriais de derivados cárneos. Revista Brasileira de Higiene e Sanidade Animal, 6(1), 1-20.

Anjos, C. M., Gois, F. D., \& Pereira, C. M. C. (2018). Desmistificando a carne suína. PUBVET, 12(12), 1-9. DOI: https://doi.org/10.31533/pubvet.v12n12a227.1-9

ANUALPEC. (2019). Anuário da Pecuária Brasileira (20th ed., Vol. 1). Instituto FNP.

Bezerra, J. M. M., Cavalcante Neto, A., Silva, L. da P. G., Lui, J. F., Rodrigues, A. E., \& Martins, T. D. D. (2007). Caracterização do consumidor e do mercado da carne suína na microrregião de Campina Grande, Estado da Paraíba. Ciência Animal Brasileira, 8(3), 485-494.

Dueli, J. S., Xavier, L. M., Fausto, M. C., da Cunha, A. F., \& Pinto, R. (2018). Perfil de consumo e percepção da qualidade da carne suína por acadêmicos de ensino superior - Viçosa, MG. Revista Científica UniScientiae, 1(2), 95-105. DOI: http://dx.doi.org/10.7213/cienciaanimal.v8i4.11006

FAPRI. (2019). Food and Agricultural Policy Research Institute (W. A. O. Database (ed.)). Food and Agricultural Policy Research Institute; Iowa State University and University of Missouri-Columbia . http://www.fapri.iastate.edu/tools/outlook.aspx

Gentilini, F. P., \& Anciuti, M. A. (2013). Tópicos atuais na produção de suínos e aves (p. 271 p.). Instituto Federal Sul-rio-grandense: Pelotas.

Guerrero, A., Rivaroli, D. C., Sañudo, C., Campo, M. M., Valero, M. V., Jorge, A. M., \& Prado, I. N. (2018). Consumer acceptability of beef from two sexes supplemented with essential oil mix. Animal 
Production Science, 58(9). https://doi.org/10.1071/AN15306

Kirinus, J. K., Fruet, A. P. B., Klinger, A. C. K., Dörr, A. C., \& Nörnberg, J. L. (2013a). Caracterização do consumo de carne suína da população de Xanxerê, Santa Catarina, Brasil. Monografias Ambientais, 12(12), 2776-2784. DOI: 10.5902/22361170

Kirinus, J. K., Fruet, A. P. B., Klinger, A. C. K., Dörr, A. C., \& Nörnberg, J. L. (2013b). Relação entre faixas de renda e o perfil dos consumidores de carne bovina da região sul do Brasil. Revista Monografias Ambientais, 12(12), 2776-2784. DOI: https://doi.org/10.5902/2236130810424

Magalhães, M. L., \& Magalhães, C. F. (2017). Biosseguridade na produção de suínos. Investigação, 16(1), 25-31. DOI: https://doi.org/10.26843/investigacao.v16i1.1728

Merlini, L. S., Frasquette, L. T., Sposito, P. H., Dutra, H. M., \& Begotti, I. L. (2014). Caracterização do consumidor e do mercado da carne suína no município de Umuarama-Paraná-Brasil. Enciclopédia Biosfera, 10(18), 833-839.

Oliveira, A. P., Silva, C. P., Santana Júnior, H. A., Santos, M. S., Brito, J. M., Mendes, F. B. L., \& Santana, E. O. C. (2017). Principais aspectos considerados por consumidores na aquisição e consumo de carne suína em Colônia do Piauí-PI. Arquivos de Ciências Veterinárias e Zoologia Da UNIPAR, 20(2), 71-77. DOI: https://doi.org/10.25110/arqvet.v20i2.2017.5810

Orsolin, D., Steffens, C., Rosa, C. D., \& Steffens, J. (2015). Redução do tempo no processo de cozimento de mortadela e avaliação da qualidade final do produto. Ciência Animal Brasileira, 16(4), 589-597. DOI: https://doi.org/10.1590/1089-6891v16i430548

Pessoa, R. M. S., Gois, G. C., Silva, A. A. F., Ferreira, J. M. S., Matias, A. G. S., Campos, F. S., Lima, C. A. B., Rodrigues, R. M. A., \& Santos, L. de F. D. (2018). A percepção do consumidor de carne ovina e caprina no município de Olho d'Água-PB. PUBVET, 12(15), 1-6. DOI: https://doi.org/10.22256/pubvet.v12n5a96.1-6

Pinheiro, F. A., Cardoso, W. S., Chaves, K. F., Oliveira, A. S. B., \& Rios, S. A. (2011). Perfil de consumidores em relação à qualidade de alimentos e hábitos de compras. UNOPAR - Científica Ciências Biológicas e Da Saúde, 13(2), 95-102.

Resende, C. M. C., \& Campos, R. M. L. (2015). Benefícios da carne suína na saúde do consumidor. Revista Eletrônica Nutritime, 12(6), 4457-4463.

Santos, A. S., Palheta, I. C., Santos, R. P., Nascimento, T. S., \& Melo, J. D. (2017). Frequência e preferência do consumo de carnes bovina, suína e aves por praticantes de exercícios físicos nas academias da cidade de Redenção-Pará. Revista Brasileira de Nutrição Esportiva, 11(61), 87-92.

Santos, E. L., Silva, J. C., Nascimento, R. N., Garcia, P. H. M., Silva, S. J. C., Lima, M. R., OliveiraAmorim, J. M., \& Sampaio, C. A. (2019). Perfil dos consumidores de carne suína e derivados em Satuba-Alagoas. Revista Científica Rural, 21(1), 142-157.

Santos, Elton Lima. (2012). Mercado consumidor de carne suína e seus derivados em Rio Largo-AL. Acta Veterinaria Brasilica, 6(3), 230-238. DOI: https://doi.org/10.21708/avb.2012.6.3.2968

Silva, J. P., \& Silva, L. da P. G. (2010). Estudo e avaliação do consumidor de carne suína "in natura" e industrializada na microrregião de Guarabira-PB. Agropecuária Científica No Semiarido, 5(1), 57 61. DOI: http://dx.doi.org/10.30969/acsa.v5i1.49

Soletti, I. (2011). Análise sensorial dinâmica de bacon defumado com madeiras de reflorestamento: Um estudo com consumidores. 75f. Dissertação (Mestrado), Escola Superior de Agricultura "Luiz de Queiroz" - USP, Piracicaba, São Paulo. DOI: 10.11606/D.11.2019.tde-17012019-160312

Souza, C. C., Gabriel, R., Reis Neto, J. F., \& Frainer, D. M. (2016). A percepção de compradores sobre a qualidade da carne suína in natura no mercado varejista de Campo Grande (MS). Extensão Rural, 23(3), 151-168.

Vedovatto, E., Steffens, C., Cansian, R. L., Backes, G. T., \& Verlindo, R. (2019). Avaliação de diferentes culturas starters na elaboração de salame tipo italiano. Ciência Animal Brasileira, 20, 124. DOI: https://doi.org/10.1590/1809-6891v20e-47777

Recebido: 10 de dezembro, 2019 Aprovado: 18 de janeiro, 2020

Disponível online: 9 julho, 2020.
Licenciamento: Este artigo é publicado na modalidade Acesso Aberto sob a licença Creative Commons Atribuição 4.0 (CC-BY 4.0), a qual permite uso irrestrito, distribuição, reprodução em qualquer meio, desde que o autor e a fonte sejam devidamente creditados. 